\title{
Considerations on Speaking Skills: Essence of Learning and Teaching Speaking
}

\author{
Betul Ayse Sayin \\ Canik Basari University, Samsun, Turkey
}

\begin{abstract}
Acquisition of speaking skills is among the most essential language skills for students currently, especially among Turkish students since language competency is measured through speaking. Every language learner desires to acquire correct communicative skills and fluency in speaking, while teachers aim to give the necessary education in speaking, as well. This study reveals the essence of acquiring speaking competency for learners, and how important it is to teach speaking skills with correct methods and methodology. With the questionnaire analysis on Turkish students and teachers at a Turkish university, the theoretical knowledge on "essence" is blended with the questionnaire results provided from students and teachers in order to emphasize the necessity and reach more practical solutions for the current need of learning and teaching speaking.
\end{abstract}

Keywords: speaking skills, teaching speaking, learning speaking, communicative competence, essence of speaking

\section{Introduction}

The mastery of speaking skills in English today is a priority for the majority of foreign language learners. As a result of this, learners often evaluate their success in language learning as well as the effectiveness of their English course on the basis of how much they feel they have improved in their spoken language proficiency. Oral skills have hardly been neglected in ESL/EFL courses (witness the huge number of conversation and other speaking course books in the market), though how best to approach the teaching of oral skills has long been the focus of methodological debate (Richards, 2008).

In study after study, communication skills emerge as one of the most important, if not, the most important quality that employers require of graduates. Possessing good communication skills is often seen by employers as an indicator of potential success (Harvey, 2000). In Turkish schools and colleges, it has not been the major skill to be acquired till the last decade. It has gained a gradual recognition as an important step of acquiring the target language.

Communicative competence is a dynamic rather than a static concept that depends on the negotiation of meaning between two or more persons who share the knowledge of the language. This implies the appraisal of the individuals' thinking capacity leading them to take heed of the linguistic environment, to formulate their hypothesis in an attempt to grasp the meaning of the new information, and to test the hypothesis within the context suitable to such information, i.e., "meaningful learning" as proposed by Ausubel (1968).

While communicative competence is regarded as a meaningful way of learning a language, it is seen that both Turkish teachers and students realize the necessity of speaking skills, and started to put an emphasis on

Betul Ayse Sayin, Assistant Professor, Ph.D., lecturer of English Language Teaching (ELT), Canik Basari University. 
teaching and learning speaking more than grammar and vocabulary skills. The questionnaire results emphasized the students' awareness on the importance of acquiring speaking skills, while at the same time the questionnaire on teachers displays the essence recognized on teaching speaking.

\section{Essence of Acquiring Speaking Skills (From the Students' Point of View)}

Good oral communication is essential to every aspect of life and work. Many surveys have identified it as one of the skills most highly valued by employers. People with good communication skills:

(1) can relate well to colleagues and customers;

(2) are able to get information they need from organizations and individuals;

(3) can explain things clearly and contribute to meetings and discussions;

(4) are more successful in their careers;

(5) have more positive and productive relationships with others (Cole et al., 2007, p. 2).

The demand to oral communication and speaking skills is a good motivation for learners of English to see the essence of English as a global reality and improve their ability in this respect.

While speaking skills may have been somewhat underemphasized in schools, they have not been underemphasized in the real world (Palmer, 2011). The essence given to speaking skills should be arisen day by day among students which is a real-life measure of learning a language. Some students perceive the necessity of acquiring good communication skills with self-motivation, while some do not comprehend the need for speaking even though there are examples of foreign language exposure around them from foreign films, songs, brand names, and store names to the chance of meeting a foreigner in culturally diverse big cities.

Even though many Turkish students nowadays receive foreign language education from elementary school, they need to develop new perspectives in language learning, and focus on speaking skills as a practical real-life device.

The curriculums at schools in Turkey have focused on teaching first and foremost grammar skills, and then on vocabulary till the last decade. When the foreign language education is realized to be inefficient when it comes to speaking, and when the current and increasing need for communication in target language instead of just knowing the usage is realized, learning to speak and teaching speaking gained importance at schools.

\section{Methodology I}

In order to shed light on the awareness of the students on the essence of speaking skills, a questionnaire is held on language skills among 90 prep school students at a Turkish university who are aware of importance of language learning process and language skills. The questionnaire includes six types of skills of English language; reading, writing, listening, speaking, grammar, and vocabulary. The questionnaire consists of two separate ranking parts which are aimed to measure the consistency among the language skill selection of students. The ranking parts of the questionnaire bring the question of whether students simultaneously show success in the language skill which they regard as more important. In fact, it is expected to come out with difference in the results in order to support the research proposal of this study.

\section{Results I}

The first part of the questionnaire reveals the opinion of students about the essence of speaking skills. They are asked to rank the skills from the one that they think is more important to the less (from 1 to 6 ). 
Table 1

Ranking of the Skills of English Language From More Important to the Less

\begin{tabular}{llll}
\hline & Frequency & Percent (\%) & Mean \\
\hline Reading & 5 & 5.62 & 4.0111 \\
Writing & 2 & 2.2 & 4.2444 \\
Listening & 12 & 13.3 & 3.2444 \\
Speaking & 38 & 42.2 & 2.1778 \\
Grammar & 13 & 14.4 & 4.1333 \\
Vocabulary & 22 & 24.4 & 3.1111 \\
\hline
\end{tabular}

As shown in Table 1, speaking skills display the highest rank with the frequency rate of 38 and with a percent of 42.2 which explicitly reveals that majority of students regard speaking skills highly important. The average mean of speaking shows the lowest degree (2.1778) which also reflects the first rank among six skills.

In the next half of the questionnaire, it is asked to rank the skills in the order from the one that they are most successful to the least. The questionnaire item aims to find out whether their answers in both ranking questions on skills reflect similarity.

Table 2

Ranking of the Skills of English Language From the One That the Students Are Most Successful to the Least

\begin{tabular}{llll}
\hline & Frequency & Percent (\%) & Mean \\
\hline Reading & 15 & 16.7 & 3.2444 \\
Writing & 5 & 5.6 & 3.7778 \\
Listening & 12 & 13.3 & 3.3556 \\
Speaking & 13 & 14.4 & 4.0222 \\
Grammar & 24 & 26.7 & 3.3444 \\
Vocabulary & 21 & 23.3 & 3.1889 \\
\hline
\end{tabular}

Table 2 displays the difference between the two ranking items. In this questionnaire item, it is observed that speaking with a frequency rate of 13 , a percent of 14.4 is not skill that students are the most successful; on the contrary it is among the skills at which the subject Turkish students are less successful with a mean of 4.0222. It can be deduced from Table 2 that while writing skills is the one at which the students are the least successful, speaking skills of Turkish students need to be improved, as well. Considering both Table 1 and Table 2, it can be inferred that while speaking skills are regarded as more essential than the other skills, grammar and vocabulary skills still preserve their importance for students, and they study those skills more. Students do not show success in speaking as it should be.

The last part of the questionnaire includes language learning aspects. Students are asked to put a tick on the items which they think are highly important in language learning. Among 90 students, 88 students answered the last part of the questionnaire with two missing. The items are evaluated as "yes" when they put a tick, and "no" without a tick.

Table 3

Aspects of Language Learning

\begin{tabular}{llllll}
\hline & \multicolumn{3}{c}{ Yes } & No \\
\cline { 2 - 6 } & Frequency & Percent & Frequency & Percent & Mean \\
\hline Communication & 81 & 90.0 & 7 & 7.8 & 1.0795
\end{tabular}




\begin{tabular}{llllll} 
Meaning & 66 & 73.3 & 22 & 24.4 & 1.2500 \\
Sentence structure & 31 & 34.4 & 57 & 63.3 & 1.6477 \\
Oral practice & 77 & 85.6 & 11 & 12.2 & 1.1250 \\
Written practice & 44 & 48.9 & 44 & 48.9 & 1.5000 \\
Vocabulary knowledge & 75 & 83.3 & 13 & 14.4 & 1.1477 \\
\hline
\end{tabular}

It is obvious from Table 3 that "communication", "oral practice", and "vocabulary knowledge" were evaluated as highly important aspects of language learning process, while "sentence structure" and "written practice" did not convey the expected value among the subject students. The questionnaire outcomes repeat the necessity of oral communication in language learning.

While the results of the questionnaire explicitly show the inclination and awareness of students towards speaking skills, they still do not achieve success in speaking as much as in grammar and vocabulary skills which is the result of a wrong habit and failure in understanding the language learning and teaching process.

Acquiring good speaking skills is not merely the responsibility of students. Instead, it is principally upon teachers to motivate students. Students are constantly expected to show efforts to speak fluently; however, the awareness of the essence comes first so as to adopt the skill, and it needs to be achieved with mutual efforts of students and teachers. Students need to engage with the target language through in class speaking activities in order to be acquainted with the language. While task-based speaking activities, oral presentations, use of visual aids on contexts are helpful materials to make the students speak, "project-based learning, done well, has already been shown to be effective" (Larmer \& Mergendoller, 2012, p. 74). However, project-based learning is one of the main tools of speaking classes as well as presentations which motivate students and provide a more realistic environment.

\section{Essence of Teaching Speaking Skills}

Approaches to the teaching of speaking in ELT have been more strongly influenced by fads and fashions than the teaching of listening. "Speaking" in traditional methodologies usually meant repeating after the teacher, memorizing a dialog, or responding to drills, all of which reflect the sentence-based view of proficiency prevailing in the audio-lingual and other drill-based or repetition-based methodologies of the 1970s. The emergence of Communicative Language Teaching (CLT) in the 1980s led to changed views of syllabuses and methodology, which are continuing to shape the approaches to teaching speaking skills today. Grammar-based syllabuses were replaced by communicative ones built around notions, functions, skills, tasks, and other non-grammatical units of organization (Richards, 2008).

A useful framework for organizing lesson is the Presentation, Practice, and Production (PPP) model. PPP is particularly effective for lower language skills levels where students have little input apart from their teacher and course books (Baker \& Westrup, 2003). Students are going to be active in the Practice, and especially Production phases. According to Baker and Westrup (2003), if the students have a high level of English skills, another possibility is to start with the Production phase. Students may already know a lot of grammar and vocabulary and may need practice in using it in less structured activities. In this case, one monitors the speaking activity carefully, dealing with errors and sorting out any difficulties later, even sometimes going back to a brief presentation phase and practice phase if needed.

PPP refers to the lesson structure that can be used for the teaching of speaking as well as other language skills. To help students develop communicative efficiency in speaking, instructors can use a balanced activities 
approach that combines language input, structured output, and communicative output (Burkart, 2003-2004).

Language input comes in the form of teacher talk, listening activities, reading passages, and the language heard and read outside of class. It gives learners the material they need to begin producing language themselves.

Language input may be content oriented or form oriented.

Content-oriented input focuses on information, whether it is a simple weather report or an extended lecture on an academic topic. Content-oriented input may also include descriptions of learning strategies and examples of their use.

Form-oriented input focuses on ways of using the language: guidance from the teacher or another source on vocabulary, pronunciation, and grammar (linguistic competence); appropriate things to say in specific contexts (discourse competence); expectations for rate of speech, pause length, turn-taking, and other social aspects of language use (sociolinguistic competence); and explicit instruction in phrases to use to ask for clarification and repair miscommunication (strategic competence) (Burkart, 2003-2004, p. 2).

In the presentation part of a lesson, an instructor combines content-oriented and form-oriented input (Burkart, 2003-2004). However, when learners first begin to speak in another language, their speaking will need to be based on some form-focused learning. An effective way to begin is to base speaking on some useful simple memorized phrases and sentences. These may be greetings, simple personal descriptions, and simple questions and answers. These can be practiced in "repetition drills". The teacher says a phrase or sentence several times and then asks the learners to repeat. Some learners can be called on to repeat individually, and then the class may repeat together.

Drills play a useful part in a language course in helping learners to be formally accurate in their speech and in helping them to quickly learn a useful collection of phrases and sentences that allow them to start using the language as soon as possible. The use of drills, however, should be seen as merely one kind of form-focused activity that needs to be balanced with other types of form-focused activities, as well as with meaning-focused and fluency development activities (Brown \& Nation, 1997). Language learners should also be exposed to and given opportunities to practice and use meaning-focused communication, in which they must both produce and listen to meaningful oral communication.

In meaning-focused speaking activities, it is necessary to make sure that the activity is actually developing the learner's ability to use language items in the process of speaking. In a meaning-focused activity, the speaker's and the listeners' attention is on the message being communicated (Brown \& Nation, 1997). Today's world requires that the goal of teaching speaking should improve students' communicative skills, because only in that way students can express themselves and learn how to follow the social and cultural rules appropriate in each communicative circumstance. Communicative Language Teaching (CLT) and collaborative learning serve best for this aim. EFL teachers should create a classroom environment where students have real-life communication, authentic activities, and meaningful tasks that promote oral language. This can occur when students collaborate in groups to achieve a goal or to complete a task (Kayi, 2006). Some activities to promote speaking stated in Kayi's article are discussions, role plays, simulations, information gaps, brainstorming, story-telling, interviews, story completion, reporting, playing cards, picture narrating, picture describing and finding the difference activities.

Teaching speaking is a really important part of teaching a foreign language. Leading students to acquire the correct communicative and collaborative skills is highly essential rather than using only memorization 
techniques. Teaching interactive skills is not only necessary for life, but also meaningful and enjoyable for students. For that reason, it is crucial for teachers to use Communicative Language Teaching Method in their speaking classes together with choosing the correct type of language input and speaking function the students need.

According to a study held among foreign language teachers in Turkey by Atay, Kurt, Çamlıbel, Kaşlıoğlu, and Ersin (2009), teachers are concerned to teach English predominantly for practical purposes more than providing language knowledge and skills. This is a good sign that reflects the awareness of teachers for the use of language instead of simply teaching the usage. Yet, it is necessary to learn the point of view of teachers on how to teach speaking and what aspects of teaching speaking they pay attention to.

\section{Methodology II}

The study is held among 20 English language teachers working at a university in Turkey. The participants are selected arbitrarily from one university who teach speaking to different level groups.

The first section of the questionnaire involves common speaking activities used in classes. The activities are chosen basically by taking the techniques used in Communicative Language Teaching. Some of the activities are taken from other methods and language classes. The teachers are asked to indicate the frequency of the activities they use in their speaking classes in order to see how often they apply communicative activities. The responses are evaluated with descriptive statistics, and given in the descending order to make the data more understandable.

Table 4

The Most Common Activities Used in Speaking Classes

\begin{tabular}{lllll}
\hline & $\mathrm{N}$ & Mean & Std. Deviation & Std. Error Mean \\
\hline 1. Real life questions & 20 & 4.6500 & .48936 & .10942 \\
2. Picture descriptions & 20 & 3.6000 & .94032 & .21026 \\
3. Brainstorming & 20 & 3.5500 & 1.05006 & .23480 \\
4. Games & 20 & 3.5000 & .76089 & .17014 \\
5. Group discussions & 20 & 3.5000 & 1.00000 & .22361 \\
6. Problem solving tasks & 20 & 3.2500 & .78640 & .17584 \\
7. Role plays & 20 & 3.0500 & .75915 & .16975 \\
8. Drills & 20 & 3.0000 & 1.25656 & .28098 \\
9. Storytelling & 20 & 2.7500 & 1.01955 & .22798 \\
\hline
\end{tabular}

The responses indicate that the most commonly used speaking activity is a CLT-based activity "real life questions" with a frequency of 4.65. The use of authentic materials such as newspaper articles, advertisements, menus, or timetables which aid to discussion and question-answer activities are regarded as real communicative activities. The second common activity is "picture descriptions" with a frequency of 3.6 which is also a technique used in CLT. "Brainstorming" is the third most common activity with a frequency of 3.55. The table displays that "role plays", "drills", and "storytelling" are not used as often as other activities. Despite the importance of role play in approaches which take speaking skills as a base, it can be deduced that Turkish teachers do not apply the method in their language classes in the expected frequency.

The second section of the questionnaire involves 14 items which aim to evaluate the considerations of teachers on self-attitudes about teaching speaking. 
Table 5

Evaluation of Teacher's Self-attitudes About Their Speaking Classes

\begin{tabular}{lllll}
\hline & $\mathrm{N}$ & Mean & Std. Deviation & Std. Error Mean \\
\hline 1. I find it easy to get the students speak and communicate in the class. & 20 & 2.8000 & 1.19649 & .26754 \\
2. The most essential factor for a student to learn speaking is to speak a & 20 & 4.0000 & .91766 & .20520 \\
lot in the target language. & 20 & 3.0000 & .91766 & .20520 \\
3. I speak more than students do in the class. & 20 & 3.9000 & .64072 & .14327 \\
4. I use all the opportunities to let the students speak. & 20 & 3.8500 & .87509 & .19568 \\
5. I motivate my students to speak at every lesson. & 20 & 3.9000 & .78807 & .17622 \\
6. I motivate them to speak with their classmates in the class. & 20 & 4.2500 & .55012 & .12301 \\
7. I give them useful hints to improve their speaking. & 20 & 3.5500 & .75915 & .16975 \\
8. I lead them to use their grammar knowledge to speak. & 20 & 4.2500 & .63867 & .14281 \\
9. I lead them to use their vocabulary knowledge to speak. & 20 & 3.8947 & .73747 & .16919 \\
10. I teach them how to become autonomous learners. & 20 & 4.3000 & .73270 & .16384 \\
11. I teach them socio-cultural knowledge of the target language. & 20 & 2.7500 & 1.11803 & .25000 \\
12. I instantly correct mistakes of my students at the time of speaking. & 20 & 2.9500 & .88704 & .19835 \\
13. My students are quite successful in speaking. & 20 & 3.6000 & .82078 & .18353 \\
14. I consider myself successful in teaching speaking. & & & &
\end{tabular}

The Table 5 displays the descriptive statistics. Teacher responses show high frequencies on the items 2,7 , 9, and 11. Participants believe that it is necessary for students to speak a lot in order to learn and improve speaking skills as indicated in item 2 with 4.00 . It can be deduced that teachers pay more attention to vocabulary use and development rather than grammar use. The high frequency of item 9 in leading students to use vocabulary knowledge also indicates that teachers focus more on vocabulary knowledge. Besides, the mean frequency of 4.25 of item 7 shows that teachers try hard to give useful hints to improve students speaking. In this regard, the highest frequency of 4.30 of item 11 on teaching socio-cultural knowledge of the target language supports item 7. Moreover, items 4, 6, and 10 display that teachers try their best to let the students speak in the class, motivate them and help them become autonomous learners. As a result of these efforts, in item 14, teachers reflect high frequencies on self-evaluation, and regard themselves successful in teaching speaking. In item 1, it can be deduced that teachers are aware of the difficulties of teaching speaking, and item 13 illustrates that students do not show high success in speaking skills since items 13 and 14 are not positively correlated. The data of the Table 5 above illustrates that teachers believe they do their best to improve speaking skills of students.

\section{Results and Discussion}

This study examines the ideas of students and teachers separately in order to identify the given importance to speaking skills by each side. The results of the study may be obtained from students of one particular university; however, it is believed to reflect the general idea of Turkish students of that age who focus on learning a foreign language. Likewise, the participant teachers were not from various institutions, yet they intensely engaged in teaching English, focused on teaching skills separately, and paid attention to teaching speaking, as well. The groups are used to be a sample to reflect the idea that is desired to be presented for the language learning process in Turkey.

The sample population of students and teachers displayed positive attitudes and ideas towards the acquisition of oral skills. Despite the low success of students in speaking which was indicated in both student 
and teacher questionnaires, it can be stated that both teachers and students lean to speaking currently.

It can directly be dedicated from both questionnaire results that learning and teaching of oral skills carry high importance among university students and teachers in Turkey. They both have gained the awareness on the essence of acquiring speaking skills in language learning and teaching. It is a good sign for Turkish students and teachers towards a change in language learning from a structural approach to a communicative approach. It is strongly believed and hoped that the realization and recognition among teachers and students will spread to primary and secondary educational institutions and larger groups.

Students urgently need to gain self-autonomy and self-responsibility of their learning, and move towards their goals. Receiving correct acquisition of speaking skills is related basically with self-determination and self-study guided by the teacher.

It is also believed that effective teaching can be achieved only if it is reflective. If teachers analyze the process of teaching and the outcomes, and based on their analysis and self-assessment, if they try to improve themselves and classes even when it is already good enough, it can be remarked that students will improve and show success, as well.

\section{Conclusion}

As Souza (1994) states, considering the learner's communicative needs where communicative competence is seen as an oral phenomenon nowadays, one assumes that production of materials must appeal to the development of communicative competence. While oral skills are considered as a global necessity in all fields, it is expected that both students and teachers gain this understanding and confidence during their language learning and teaching process. The acquisition and development of speaking skills is related with mutual responsibility of teachers and students. As a productive skill, speaking requires more practice and effort to become successful. The questionnaire results revealed a positive attitude and understanding towards this essential skill. It is hoped that speaking is soon going to be the main skill taught and acquired at every section of Turkish educational institutions as well as other countries in the world.

\section{References}

Atay, D., Kurt, G., Çamlıbel, Z., Kaşlıoğlu, Ö., \& Ersin, P. (2009). The role of intercultural competence in foreign language teaching. Inonu University Journal of Faculty of Education (Special Issue), 10(3), 123-135.

Ausubel, D. P. (1968). Educational psychology: A cognitive view. New York: Holt, Rinehart and Winston.

Baker, J., \& Westrup, H. (2003). Essential speaking skills. London: Continuum and Voluntary Service Overseas.

Brown, R. S., \& Nation, P. (1997). Teaching speaking: Suggestions for the classroom. T. O. Editor (Ed.). Retrieved from http://jalt-publications.org/old_tlt/files/97/jan/speaking.html

Burkart, G. S. (2003-2004). Teaching speaking. Retrieved from http://www.nclrc.org/essentials/speaking/spindex.htm

Cole, D., Ellis, C., Mason, B., Meed, J., Record, D., Rosetti, A., \& Willcocks, G. (2007). Teaching speaking and listening: A toolkit for practitioners. Bristol: Portishead Press.

Harvey, L. (2000). New realities: The relationship between higher education and employment. Tertiary Education and Management, 3-17.

Kayi, H. (2006, November 11). Teaching speaking: Activities to promote speaking in a second language. Retrieved from http://iteslj.org/Techniques/Kayi-TeachingSpeaking.html

Larmer, J., \& Mergendoller, J. R. (2012). Speaking of speaking. Educational Leadership, 70(4), 74-76.

Palmer, E. (2011). Well spoken: Teaching speaking to all students. Portland, Maine, USA: Stenhouse Publishers.

Richards, J. C. (2008). Teaching listening and speaking: From theory to practice. NY, USA: Cambridge University Press.

Souza, M. B. (1994). Motivating learners: Using songs in the classroom. In V. J. Leffa (Ed.), Autonomy in language learning (p. 341). Porto Allegre: Universidade Federal do Rio Grande do Sul. 